\title{
The idea of animal welfare - developments and tensions
}

Sandøe, Peter; Jensen, Karsten Klint

Published in:

ICVAE - First International Conference on Veterinary and Animal Ethics 2011

Publication date:

2011

Document version

Publisher's PDF, also known as Version of record

Citation for published version (APA):

Sandøe, P., \& Jensen, K. K. (2011). The idea of animal welfare - developments and tensions. In C. Wathes, S.

May, S. McCulloch, M. Whiting, \& S. Corr (Eds.), ICVAE - First International Conference on Veterinary and

Animal Ethics 2011 (pp. 11-17). The Royal Veterinary College, University of London. 


\title{
2. The idea of animal welfare - developments and tensions \\ Peter Sandøe and Karsten Klint Jensen \\ University of Copenhagen
}

\begin{abstract}
This paper focuses on developments and tensions within the idea of animal welfare. There is divergence among those who believe in the idea of animal welfare. First, we discuss what it takes for farm animal welfare to be good enough. How far should society go beyond the starting point of the Brambell Committee, which was to prevent avoidable suffering? Secondly, we turn to the tricky question of how welfare should be distributed between animals. Here a tension, within the concept of animal welfare, between a focus on the individual animal and one on the herd, flock or shoal is pointed out. Finally, the role of economic considerations in efforts to improve animal welfare, given that animal production takes place in a global market with free movement of products across borders between countries with varying standards of animal welfare, is touched upon.
\end{abstract}

Key words animal welfare, Brambell Committee, unnecessary suffering, fairness to animals, animal welfare legislation

\section{Background - The Modern Idea of Animal Welfare and the Brambell Report}

The modern idea of animal welfare was given its first clear statement in the Brambell report (Brambell 1965). Although the term welfare has been applied to animals since the $18^{\text {th }}$ century (Radford 2001, p. 261), the Brambell report signalled a change in the rationale towards animal protection. Earlier animal protection was specifically set up to protect animals from pointless (i.e. wanton) cruelty. This meant that constructive uses of animals - specifically in agricultural production - were not hindered by legislation at this time. Animal welfare, in the modern sense of the word, on the other hand, aims to protect animals in farm animal production against rational over-use.

The Brambell Committee was set up by the British government following the public outcry about intensive livestock farming prompted by Ruth Harrison's book Animal Machines, published in 1964. The recommendations of the committee formed the basis of subsequent British and European animal welfare legislation. Intensification of animal production in western countries was encouraged by public policies put in place immediately before, during and after the Second World War. These promoted the development of abundant, cheaper food. As a result, animal production became much more efficient, as measured by the cost of producing each egg, or kilogram of meat, or litre of milk. The pressure for efficiency subsequently became market-driven, with competition between producers and between retailers to sell food as cheaply as possible, and thereby acquired its own momentum. In some ways this can be viewed as a success story.

At the same time, as Ruth Harrison pointed out, the advances gave rise to conflicts between productivity and the interests of the animals; and the animals invariably paid the price. Typically they were given less space per individual than previously, and many were reared in barren environments and were unable to exercise their normal range of behaviours. Also, as has now become clear, higher productivity was boosted by genetic selection, which has in many cases been accompanied by production-related diseases.

The Brambell report focused mainly on the negative effects that modern intensive production systems can have on animals, particularly suffering. The fact that such suffering was seen as a moral problem was nothing new, however. Rather, the new developments were as follows: first, efficient production and animal suffering were seen as two sides of the same coin, whereas earlier it had been argued by producers that increased productivity entails good welfare (Rollin 2005, p.16); and second, that demand for cheap food is no longer assumed to overrule concerns about the welfare of farm animals.

Another new and influential idea presented in the Brambell report was that farm animals have "behavioural urges", often frustrated in intensive confinement systems, which they need to perform to avoid suffering (Mench 1998). This led to the statement of a general principle of animal welfare according to which farm animals should 
be free "to stand up, lie down, turn around, groom themselves and stretch their limbs" (the so-called Brambell freedoms) (Brambell 1965, p. 13).

Brambell broadened the received conception of what counts as suffering. The committee insisted that suffering covers much more than pain, and should include discomfort and stress (understood to cover a wide range of mental states including frustration and fear). In this, the Brambell report, besides presenting its own ideas on behavioural needs, drew on results presented earlier that year in the Littlewood Report of the Committee on Experiments on Animals (Littlewood 1965).

A final and very influential thought found in the Brambell report was that studies based on methods from physiology and ethology are necessary elements of animal welfare assessment. This was given great weight when the conclusions of Brambell were implemented. By requiring agricultural reform to be underpinned by scientific evidence, the government, on the one hand, undertook to set up new research, and on the other, bought time before having to embark on controversial legislation.

The Brambell report and similar initiatives in other European countries set off a process of legal reform, which have improved the conditions of farm animals in the UK and the rest of Western Europe. However, the early formulations of animal welfare, beginning with the Brambell report, remained loyal to the basic idea of farm animal production as a legitimate human endeavour. This in many ways curbed the criticisms that were levelled against modern intensive animal production, as we shall now try to explain:

First, the focus was mainly on the absence of suffering; there was little or no mention of positive welfare. Even the central principle of the Brambell report, that animals require certain basic freedoms (later developed into the Farm Animal Welfare Council's Five Freedoms (FAWC 2009)), was understood to be violated only when the infringement of a freedom leads to suffering. Second, the protection from suffering secured in most animal welfare legislation applied only to so-called "unnecessary suffering". This in practice allowed a number of welfare problems to be accepted as necessary, for example those related to keeping laying hens in battery cages. Third, claims regarding animal welfare could only be made on the basis of solid scientific evidence; so the burden of proof lay with those who claimed that animal welfare was threatened. Fourth, the whole idea that intensive animal production was the right solution to food production was not being questioned.

In the past, a significant amount of literature has focused on the limitations about the definition of animal welfare. It has been argued that a correct definition presupposes an ideal of what counts as a good animal life and that there is conceptual space for alternatives to the kind of negative hedonism, i.e. the view that only prevention of suffering matters as described above (Fraser 1997 and 1999; Appleby and Sandøe 2002; Sandøe and Christiansen 2008, ch.3). This shows that animal welfare is not just based on science but also has an underpinning in values.

For example, it can be claimed that animals should be able to perform natural behaviour not only for the reason that this prevents suffering (the key rationale presented in the Brambell report), or because doing so generates pleasure, but also because this is of value in its own right. This kind of perfectionist view, focusing on animals doing well rather than just feeling well, seems to be ignored in the dominant conception of animal welfare. In fact, studies of popular perceptions show that the ordinary person's view of animal welfare is more perfectionist than the dominant expert view (in which there is an almost exclusive focus on suffering and disease (Las-
sen et al. 2006)).

In this paper, we focus on developments and tensions within the idea of animal welfare. We ask what it takes for farm animal welfare to be good enough, how this welfare should be distributed between animals, and how animal welfare can be promoted in a globalized world with free trade of animal products.

There seems to be a difference between people who have concerns about animal welfare, yet believe in the permissibility of animal use as long as those concerns are fulfilled, and animal rights advocates (and others) who question the very legitimacy of human use of animals. However, even among those in the first of these groups call them "welfarists" - differences have developed over the ideal balancing of animal welfare and human benefits. 
In the following sections, we outline three lines of discussion showing divergences among welfarists. First, we discuss how far to go beyond the starting point of the Brambell Committee, which was to prevent avoidable suffering. Secondly, we discuss a tension, within the concept of animal welfare, between a focus on the individual animal and one on the herd, flock or shoal. Finally, we touch upon the role of economic considerations in efforts to improve animal welfare, given that animal production takes place in a global market with free movement of products across borders between countries with varying standards of animal welfare.

\section{From "No Unnecessary Suffering" to "A Good Life" for Animals}

The Brambell report recommended that animal welfare legislation "should make it an offence to cause, or permit to continue, avoidable suffering" (Brambell 1965, p. 61). Here, suffering should be understood in a broad sense, including not only pain but also discomfort and the feeling of stress. Few would deny that this is a laudable goal. However, it seems perfectly reasonable to ask, first, how avoidable is to be defined, and second, why we should not go further than that?

There is an element of truth in the idea of that some animal suffering is unavoidable: the only completely effective way of preventing suffering in animals is not to bring them into existence. To experience the good moments of life, every animal (including humans) will invariably have to experience some of the bad ones too.

However, there is much more to the idea of unavoidable suffering than just that. What is at issue here is suffering that is necessary given the goal of efficient animal production. For example, the Brambell report did not recommend a ban on battery cages, but only that there should be a limit on stocking densities in such cages. This was not because cages do not cause suffering, but because other production systems which were commercially viable had similar problems. The more fundamental question, whether there ought to be a commercial mass production of cheap eggs, is not asked.

The British legislation following Brambell used the term unnecessary suffering. But again, there are different ways of understanding what qualifies as necessary suffering. At one end of the scale, all suffering that are due to factors that enhance the efficiency of production will be deemed necessary. Here unnecessary suffering could be called a remnant of the old notion wanton cruelty. At the other end of the scale, only suffering that is necessary for the greater good of the animals, such as living through periods of disease or inter-group fighting for rank, will count as necessary. Most animal welfare legislation draws the line somewhere between these two extremes. For example, in British legislation one of the criteria that must be met for suffering to be deemed necessary is that what causes the suffering must be for a legitimate purpose and proportionate to that purpose (Animal Welfare Act 2006, Section 4, Sub-section 3). Hence, the term "unnecessary suffering" is not doing any useful work of clarification here; it rather serves to cloud underlying ethical issues about how to balance animal welfare against efficient animal production. Of course, this problem does not go away when the term is avoided, as it is e.g. in current EU legislation and in the legislation of some other European countries, including Denmark.

Turning to the question of whether to be more progressive, one can ask why the focus is on avoiding unnecessary suffering. Why should we not also focus on the unnecessary withholding of positive welfare? If, at no significant cost, it is possible to give animals opportunities to explore, eat preferred food, or otherwise engage in behaviours which give pleasure, it seems wrong not to enable this.

In a report published in 2009, the Farm Animal Welfare Council (FAWC) raised the issue of the level of animal welfare to aim for. FAWC drew a distinction between three levels of quality of life that can be achieved by an animal: a life not worth living, a life worth living, and a good life. The first is a life where suffering outweighs pleasure and therefore a life that should be terminated for the sake of the animal in question (or husbandry changed for the better). In a life worth living, the good moments outweigh the bad ones, and therefore such a life is worthwhile. However, to aim to give animals lives worth living is not to aspire very high. A life worth living will cover a range from a life barely worth living to a life full of happy and pleasurable moments; and the lower end of that range is really not very good.

FAWC recommended, as a minimal condition, that "the intention of British policy should be that an animal kept in full compliance with the law should have a life worth living" (FAWC 2009, p. 19). This would mean that 
it is enough, legally speaking, to provide animals with conditions ensuring that it would not be better for the animal to be euthanized than to go on living. It is not entirely clear whether this goal signalled real progress or, if taken literally, mandated serious deterioration relative to the status quo.

However, an important subject is raised here, which is that however good the law is there will always be room for improvement. And there will probably have to be different levels of welfare. Besides the legal minimum, which ideally will guarantee the animals more than a life barely worth living, there will be room also for production systems that guarantee a higher level of welfare. An issue here, also addressed by FAWC, is how to safeguard that products sold with a claim to enhanced animal welfare deliver on what they promise.

To deal with this issue a new wave of animal welfare research has developed since the 1990s. The focus of this work is on measuring animal welfare at the farm or group level. Whereas earlier studies of animal welfare focused chiefly on the environment in which the animals are raised, new methods have been developed which allow one to gauge welfare outcomes. These methods may turn out to be instrumental in raising welfare standards in a way that genuinely benefits the affected animals. However, they also give rise to challenging questions about how the interests of the individual are to be balanced against those of the herd. To this we now turn.

\section{From the Individual to the Herd}

According to Brambell's recommendations - and indeed many subsequent initiatives in European countries and at the EU level - the main vehicle for improving farm animal welfare is regulation. To date, European regulation has focused largely on minimum standards for housing and animal handling, but it is recognised that variations in management can lead to welfare problems even on farms satisfying the legal minimum.

Attempts to deal with the management factor through higher minimum standards may lead to a bureaucratic system of rules and controls. It is not clear that this benefits the animals. Except in certain clear-cut areas, like the handling of some diseases, management regulation has therefore tended to rely on a somewhat vague notion of good practice. However, since, to attract penalties, violations of good practice must be severe and made with intent or gross negligence, this has created a grey zone in which the regulatory authorities encounter poor welfare within the rules. Naturally, this generally is not received well when explained to the public.

Currently, therefore, the regulation of farm animal production is undergoing a transformation. One influential idea is to motivate farmers to improve welfare with incentives linked to welfare outcomes. Rather than telling the farmer how to manage his animals, a limit is set on the prevalence of a certain welfare problem. Using measures of welfare on-farm or at slaughter the authorities can then check whether a given farm is within the limits. When the prevalence of the problem on a farm is too high, then the farmer can be required to develop a plan to improve matters. In severe cases, the farmer can be fined or face a restriction on production.

In some countries, certain welfare problems - notably, foot-pad dermatitis in broilers and shoulder lesions in sows - have been successfully managed by this approach. At the same time there is a change of focus from the protection of each individual to the minimization of welfare problems at the group level. For example, in Denmark, at slaughter 100 chicken feet from each batch of broiler chickens are inspected for foot-pad dermatitis. Each foot is evaluated on a point-scale: "no foot-pad lesions" scores 0 points, "few and minor lesions" attracts 1 point, and "many or severe lesions" scores 2 points.

Using this information, batches are divided into three categories: Category A, up to 40 points; category B, between 41 and 80 points; and category $\mathrm{C}$, between 81 and 200 points. Farms with birds in category $\mathrm{A}$ are given the all-clear. When a batch is in category $\mathrm{B}$ a warning is given to the farmer. When a batch is in category $\mathrm{C}$ (or there are repeated cases of category $\mathrm{B}$ ), then the farmer is reported to the authorities. Reported farmers receive an instruction to improve the situation. They will then be under increased surveillance and may eventually be required to decrease stocking density.

The system, originally developed in Sweden (Ekstrand et al. 1998), has had a substantial effect on broiler welfare in Denmark: between 2002 and 2005 the number of batches in category $\mathrm{C}$ decreased from around 50\% 
to about $10 \%$. So, in that respect, the legislation has been very successful. However, this system potentially neglects individual animals with severe problems, for as long as a small number of animals suffer from foot-pad dermatitis, the system will pass that batch of animals.

Traditional animal welfare legislation, which stipulates minimum requirements for husbandry, treats all animals as equals. However, even on very good farms, there have always been animals that suffer, but they have not done so, as it were, in full view. The recent focus on the prevalence of problems may have the implication that some prevalence of a problem is explicitly deemed acceptable, even though it might be said to violate the minimal requirements for treatment of each individual animal. It is not a solution to this dilemma to stop measuring animal welfare at farm level and thereby allow severe but preventable animal welfare problems to occur, which is what happens where authorities do not require assessments of foot-pad dermatitis. To avoid a welfare problem by not measuring it is to stick one's head in the sand.

Proposals to deal with welfare at a group level should, however, give rise to serious ethical reflection on the relation between concern about the least well off animals and those with 'average' levels of welfare. The issues are similar to those that arise about humans in a modern welfare state, for example in the distribution of health care resources.

In the EU's recent Welfare Quality ${ }^{\circledR}$ project, an attempt was made to aggregate the welfare of animals on a farm into a grade that could be compared across farms. Here the dilemma was how to weigh severe welfare problems against mild ones. The researchers chose to give priority to the worst off animals with the implication that, of two farms with the same average level of welfare, one would score lower than the other if it had more animals with severe problems (Veissier et al. 2011).

In general, developments of this kind illustrate the need to add the ethical dimension of justice to discussions of animal welfare, to focus on the distribution of welfare among the animals. A recent paper by Houe et al. (in press) makes an attempt to do this in relation to the assessment of welfare in diseased dairy cattle.

Another obstacle to the improvement of animal welfare is the effect of international free trade. This will be discussed next.

\section{Role of Economic Considerations in Animal Welfare}

The Brambell Committee saw national legislation as a main tool to secure animal welfare. However, since the remit of the committee extended only to affairs and arrangements in the UK, its report focused exclusively on British legislation. Hence Brambell's recommendations relate to changes in British animal welfare legislation. Some of them concern changes in statutory provision; others are about codes of good practice, which also play a key role in British legislation.

The committee was aware of a lack of scientific knowledge about farm animal welfare. For this reason, and to allow for flexibility to deal with new developments in agriculture, it argued that,

"it must be possible to modify any standards laid down without the necessity for constantly amending the main legislative instrument. Therefore we recommend that any Act necessary to make our recommendations effective should be in the form of an enabling Act, so that Statutory Instruments can be made to implement them and to give early effect to desirable changes which may prove necessary" (Brambell 1965, p. 60).

In this way the committee ingeniously suggested a flexible legal structure of animal welfare legislation, which has subsequently been adopted in many European countries.

The principal idea is that animal welfare is regulated by legislation stipulating requirements that guarantee a decent minimum standard of animal welfare. The committee was aware that, given the extra costs imposed on domestic farmers by the legislation, and given the risk of imports of animal products from countries with less stringent standards of animal welfare, this policy could have problems. However, it deferred this issue to the British Government: 
"... we recognise that the effect of some of our recommendations may be to increase costs in certain sectors of the industry, at least in the initial stages. We believe that public concern about animal welfare on farms is such that this will be understood and consumers will be prepared to meet any marginal extra costs. We would, however, be concerned if the standards we have recommended for adoption in this country had the result of encouraging imports produced overseas under systems contrary to these. This might largely invalidate the intention of our Report; we therefore recommend that the Government take such steps as may be practicable to ensure that it does not happen. " (Brambell 1965, p. 62)

This may have been something that a British government could deal with in 1965 . However, with the rules governing international trade today this is certainly no longer the case. Since the 1970 s the EU has placed limits on what the British government can do to regulate trade; and more recently, through international trade agreements, limits have restricted what the EU can do. Even though, in theory, WTO allows for non-discriminatory measures to protect animal life and health (cf. GATT article XX), in practice animal welfare is not recognized as a legitimate concern allowing trade restrictions and animal products appear to be sold freely across continents.

In the recent FAWC report (2009), a strategy for improving farm animal welfare is presented. The focus is not only on farm animal production in Great Britain, but also on imported animal products. Again, the tool of choice is no longer, at any rate, primarily legislation. Instead the report looks carefully at how to bring about change in the supply sources of retailers, and how to encourage consumers to demand products with high standards of animal welfare.

With this development, animal welfare can no longer be regarded as an issue to be dealt with solely by traditional experts in the field of animal welfare. When, in 1965, the Brambell Committee suggested that the British government should set up what became FAWC, they envisaged a need for the following kinds of experts on the council: "a veterinarian, an expert on animal behaviour or comparative psychology, a zoologist, or physiologist, persons knowledgeable in animal husbandry and farm buildings and a legal expert" (Brambell 1965, p. 62). What is clearly missing here is mention of experts understanding the role of markets and trade.

It was an understandable limitation of the foresight of the Brambell Committee to overlook, or downplay, the role of economics and other social sciences in the project of improving farm animal welfare. This, however, has had a lasting, negative effect on the understanding of animal welfare. Luckily things now seem to be changing for the better. Thus, for example for a number of years FAWC has had economists and other kinds of social scientists on board.

\section{Conclusions}

The work of the Brambell Committee has undoubtedly had an enormously positive effect on the welfare of billions of animals in Britain and elsewhere. This is an achievement that cannot be overstated.

However, with hindsight it can be seen that the vision of animal welfare presented in the report has some limitations. Earlier work exposed limitations in the implicit negative hedonist view on animal welfare In this paper we have discussed aspects of animal welfare regulation and assessment, including what is a fair distribution of welfare, and on how to most effectively promote animal welfare.

Briefly, we have argued: i) that discussions about animal welfare should move away from the exclusive focus on unnecessary suffering and focus more on the ideal of good welfare; ii) that there is an often overlooked issue about the fair distribution of animal welfare across animals within a herd which need to be explicitly addressed; and iii) that in promoting animal welfare in today's world, legislation is not a sufficient tool, and that those working for animal welfare should also be concerned about changing minds and moving markets.

\section{Acknowledgements}


Thanks are due to Clare Palmer, Paul Robinson, Geir Tveit and two anonymous referees for useful comments on an earlier version of this paper, and to Thorkil Ambrosen and Mie Nielsen Blom for information on the foot-pad dermatitis case.

\section{References}

Appleby, M.C. and Sandøe, P. (2002) Philosophical debate on the nature of well-being: Implications for animal welfare. Animal Welfare, 11, 283-294.

Brambell, F.W.R. (1965) Report of the technical committee to enquire into the welfare of animals kept under intensive livestock husbandry systems. (Command Rep. 2836). London: Her Majesty's Stationery Office.

Ekstrand C., Carpenter, T.E., Andersson, I., and Algers, B. (1998) Prevalence and prevention of foot-pad dermatitis in broilers in Sweden. British Poultry Science, 39, 318-324.

FAWC (2009) Farm animal welfare in Great Britain: Past, present and future. London: Farm Animal Welfare Council.

Fraser, D. (1997) Science in a value-laden world: Keeping our thinking straight. Applied Animal Behaviour Science, 54, 29-32.

Fraser, D. (1999) Animal ethics and animal welfare science: Bridging the two cultures. Applied Animal Behaviour Science, 65, 171-189.

Harrison, R. (1964) Animal machines: The new factory farming industry. London: Vincent Stuart.

Houe, H., Sandøe, P., and Thomsen P.T. (in press) Welfare assessments based on lifetime health and production data in Danish dairy cows. Journal of Applied Animal Welfare Science, published online 17 June 2011, DOI 10.1080/10888705.2011.576984

Lassen, J., Sandøe, P. and Forkman, B. (2006) Happy pigs are dirty: Conflicting perspectives on animal welfare. Livestock Science, 103, 221-230.

Littlewood, S. (1965) Report of the Departmental Committee on Experiments on Animals. (Command Rep. 2641). London: Her Majesty's Stationery Office. Mench, J.A. (1998) Thirty years after Brambell: Whither animal welfare science? Journal of Applied Animal
Welfare Science, 1, 91-102.

Radford, M. (2001) Animal welfare law in Britain: Regulation and responsibility. Oxford: Oxford Univer-
Press.

Rollin, B.E. (2005) Animal agriculture and social ethics for animals. In W.G. Pond and A.W. Bell (eds.) Encyclopedia of animal science. New York: Marcel Dekker.

Sandøe, P. and Christiansen S.B. (2008) Ethics of animal use. Oxford: Blackwell.

Veissier, I., Jensen, K.K., Botreau, R. and Sandøe, P. (2011) Highlighting ethical decisions underlying the scoring of animal welfare in the Welfare Qualityß scheme. Animal Welfare 20, 89-101. 


\section{ICVAE - First International Conference on Veterinary and Animal Ethics}

Venue: The Royal College of Physicians, London

Dates: September 12 and 132011.

Organisers: Christopher Wathes, Stephen May, Steve McCulloch and Martin Whiting of The Royal Veterinary College, University of London and Sandra Corr, University of Nottingham

Contact: cmwathes@rvc.ac.uk; +44 (0) 1707666361

Sponsors (to whom the organisers are extremely grateful):

The Wellcome Trust

The Royal Veterinary College

The Animal Care Trust

Universities Federation for Animal Welfare, UFAW

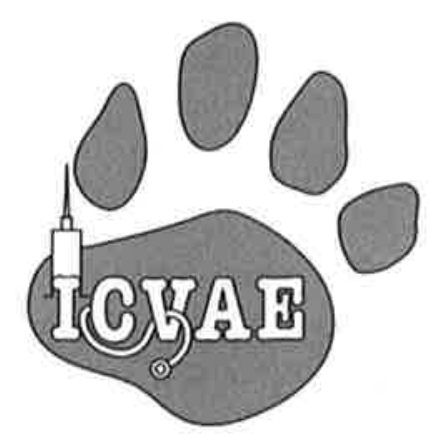

